\title{
Pre Extension Demonstration of wheat Technology Southern Agricultural Research Institute
}

\author{
Solomon Yokamo ${ }^{1}$, Melese Lema ${ }^{2 *}$, Endrias Oyka ${ }^{3}$ and Tsebaye Tsalla ${ }^{4}$ \\ Arba Minch Agricultural Research Center, Ethiopia
}

Submission: December 07, 2017; Published: March 07, 2018

*Corresponding author: Melese Lema, Arba Minch Agricultural Research Center, Ethiopia, Email: meleselema72@gmail.com

\begin{abstract}
Three varieties of wheat i.e. Shorma, Hidase and Kakaba were demonstrated with its full packages at $100 \mathrm{~m} 2$ area on two different FTCs and at 14 model farmers farm. Necessary inputs were delivered to farmers from the Arbaminch Agricultural Research Center and relevant researchers can follow-up and works in close relationship with farmers. Yield data, partial budget analysis, famers perception and preferences were collected throughout the demonstration stages. The average yield performances of the Hidase, Shorma and Kakaba were 44.82quintals/ha, 45.43quintals/ ha and 34.04quintals/ha respectively. The net benefit that were obtained from Hidase, Shorma and Kakaba were 32,636.10,33,157.65 and $23,428.7$ ETB respectively. Finally, the demonstration sites were visited by organized farmers field day and farmers select those varieties by different criteria and judge Shorma and Hidase have better disease resistance potential, drought tolerant and high yield performance. While farmers doesnt select Kakaba because of its susceptibility to diseases. Finally it is better to scale up both Shorma and Hidase in larger scale to enhance adoption and diffusion of variety to larger scales.
\end{abstract}

Keywords: Demonstration; Farmers; Varieties

\section{Introduction}

Ethiopia is one of the largest grain producers in Africa, and the second largest wheat producer in

Sub-Saharan Africa, after South Africa. Wheat production in Sub-Saharan Africa is at 10 to $25 \%$

of its potential and the region could easily grow more to improve food security. Farmers in Sub Saharan Africa produce $44 \%$ of the wheat consumed locally and import the rest from

international markets, making the region highly vulnerable to global market and supply shocks.

In Ethiopia, both the bread and durum wheat are widely cultivated in the highlands of the

country largely in the areas like South East, Central and North West parts. According to MoARD

[1], it is estimated that 1.4 million hectare of land is covered with wheat and more than 2.18

million tons are produced annually. In terms of area cultivated and annual production, wheat is

the third most important cereal crop in Ethiopia following maize and teff [2].
Accordingly, nearly 561,000 metric tons of wheat was sold by smallholders and state and private

commercial farms in 2008. However, during the same year 545,325 metric tons was

commercially imported by the government to stabilize the market. A country

domestic production was 29,163,336.88 quintals, of which $58.04 \%$ was for household

consumption, $19.59 \%$ was for seed requirement, and $20.13 \%$ was sold for domestic market and

others [2]. This indicates that, there was increment in production and marketable

volume of wheat but the current level of wheat marketed is still low and insufficient to meet the

domestic consumption and needs of newly emerging food processing industries. Moreover, in

terms of the marketable volume of wheat, it is estimated that about $21 \%$ of the domestic

production is marketed, while the bulk of the produce is retained on-farm for consumption and 
seed [3]. Wheat is mostly grown in the highlands and mid highland area of the country. Among the nine regions, Oromia and Amhara regions produce $59 \%$ and $27 \%$ of the country's wheat, respectively, with an additional nine percent coming from the Southern Nations, Nationalities, and Peoples.

Wheat has been cultivated for over 10,000 years and probably originates in the Fertile Crescent, along with other staple crops. A wide range of wheat products are made by humans, including most famously flour, which is made from the grain itself. Durum wheat (Triticum turgidum var. durum) has been cultivated in Ethiopia for thousands of years, though it is gradually being displaced by bread wheat. Durum wheat (Triticum turgidum) or pasta wheat compared with common bread wheat (Triticum aestivum) is known for its hardness, protein, intense yellow colour, nutty flavour and excellent cooking qualities. It is used to predominate in Ethiopian wheat production systems, but bread wheat has gained in popularity. However, after improved varieties are recently released and reintroduced, durum wheat is expanding both in terms of area and production due to the prevailing environmental conditions [2].

In Ethiopia, durum wheat is mainly utilized for the preparation of local traditional recipes such as dabo (Ethiopian bread), Injera (thin, flattened bread), kolo (roasted grain), nifro (boiled whole grain sometimes mixed with pulses), and kinche (crushed kernels, cooked with milk or water and mixed with spiced butter) and, to some extent, for the manufacturing of different pasta products.

Different research center releases different technologies of wheat. But farmers doesn't accept the released technology because the F-E-R (farmers-extension-researchers) relations are weak, fear for newly coming technologies and fear of failure and such trials did not took place in the study area before. Demonstrating wheat varieties on FTC and farmers field are the main tools for enhancing the adoption of technology, so that the aim of this study were to enhance rapid diffusion, adoption and dissemination of improved wheat technology, to study cost benefit analysis of the varieties and to collect feedback or farmers preference of the study areas.

Table 1: Mean yield performance of farmers.

\section{Methodology}

a. At the beginning of the pre extension demonstration of wheat technologies; two woredas namely Bonke and Arbaminch zuria woreda were selected.

b. For the commodity according to its agro ecology, target (beneficiary) farmers selected and training were delivered about on the nature of the technology from production up to marketing.

c. All necessary input was delivered to the farmers from Arbaminch Agricultural research centers ( seeds, fertilizers, etc).

d. Farmers sown the seeds on their fields and follow-ups and essential advices from relevant researchers has been taken place.

e. Finally the data were analyzed by using simple statistics and matrix rankings.

\section{Results and Discussion}

\section{Provision of training}

Before implementing the demonstration of wheat technology, training for the participant farmers and different stakeholders was provided. Fourteen participant farmers from both woreda were selected by collaboration with woreda agriculture and natural resource office. Beneficiary farmers, Kebeles development Agents and woredas experts were selected for the training. The training was provided on wheat technology pre extension demonstration of agronomic practices from land preparation to marketing. The main aims of training is to create awareness of farmers, development agents(DAs) and wored as expert on wheat technology and to compare the results finally obtained from demonstration.

\section{Yield performance of varieties under farmers field}

The wheat pre extension demonstration were implemented and the yield data were collected from fourteen farmers. The maximum and minimum yield results as well as mean yields are shown below the Table 1 .

\begin{tabular}{|c|c|c|c|}
\hline No of Farmers & Yield in Quintal (Hidase) & Yield in Quintal (Shorma) & Yield in Quintal (Kakaba) \\
\hline F1 & 50 & 49 & 37 \\
\hline F2 & 47 & 49 & 36 \\
\hline F3 & 49 & 42 & 35 \\
\hline F4 & 49 & 43 & 32 \\
\hline F5 & 48 & 45 & 29 \\
\hline F6 & 46.5 & 46.5 & 28 \\
\hline F7 & 45 & 46.5 & 35 \\
\hline F8 & 47 & 48 & 37 \\
\hline F9 & 44.5 & 45 & 36.5 \\
\hline
\end{tabular}


Agricultural Research \& Technology: Open Access Journal

\begin{tabular}{|c|c|c|c|}
\hline F11 & 42.5 & 39 & 35.5 \\
\hline F12 & 38 & 47.5 & 36.5 \\
\hline F13 & 43 & 47 & 36 \\
\hline F14 & 36 & 48.5 & 29 \\
\hline Mean & 44.82 & 45.43 & 34.04 \\
\hline Variance & 17.33 & 10.72 & 3.21 \\
\hline Stan dev & 4.16 & 3.27 & 3.2 \\
\hline LSD & & 0.27 & \\
\hline CV\% & & 8.5 & \\
\hline
\end{tabular}

Farmers Field Performance

Note: 1 quintal $=100 \mathrm{~kg}$

As the table shown above wheat demonstration work were implemented under farmers field and the mean value of yield that are obtained from farmers field from both woreda were $45.43,44.82$ and 34.04 quintal per hectare for Shorima, Hidase and kakaba respectively.

This indicated that variety Shorima performed better than others and there were $1.45 \%$ and $25.15 \%$ yiel advantage over

the Hidase and Kakaba respectively.

\section{Yield performance of FTC}

The mean yield of improved varieties of wheat technologies of FTCs as shown in the table above were 45.5 quintal per hectare Hidase, 46.5 quintal per hectare Shorma and 34.5 quintal per hectare kakaba. Shorma and Hidase showed better potential of yields than kakaba (Table 2).

Table 2: The yield performance of varieties at farmers training centers.

\begin{tabular}{|c|c|c|c|c|}
\hline \multirow{2}{*}{ Location } & \multirow{2}{*}{ Quantity } & \multicolumn{3}{|c|}{ Yield Performance } \\
\cline { 2 - 5 } & Qt/ha & Hidase & 51 & Shorma \\
\hline Zigit FTC & > & 40 & 42 & 32 \\
\hline Bonke FTC & > & 45.5 & 46.5 & 34.5 \\
\hline Over all Mean yield of FTC & >> & 44.82 & 45.43 & 34.04 \\
\hline $\begin{array}{c}\text { Farmers mean yield of } \\
\text { Zigit and Bonke(N=14) }\end{array}$ & & & \\
\hline
\end{tabular}

\section{Yield advantage and yield increase}

As shown above in the table, Shorma had $0.5 \%$ and $25.5 \%$ yield increment than Hidase and standard check(kakaba) and Hidase had 25\% yield advantage over kakaba. Generally Shorma had performed better than the two varieties which are Hidase and kakaba.but there were no significant difference between Shorma and Hidase in yield performance at both FTC and farmers field (Table 3).

Table 3: yield advantage and yield increases.

\begin{tabular}{|c|c|c|c|c|c|c|c|}
\hline \multirow{2}{*}{ Location } & \multicolumn{3}{|c|}{ Yields in Kg } & \multicolumn{2}{c|}{ Yield Increase } & \multicolumn{2}{c|}{ Yield Advantage(\%) } \\
\cline { 2 - 7 } & Hidase & Shorma & Kakaba & Shorma & kakaba & Shorma & -32 \\
\hline \multirow{2}{*}{ Zigit(N=6) } & 4825 & 4575 & 3283 & -250 & -1542 & 7 & -17.3 \\
\hline \multirow{2}{*}{ Bonke(N=8) } & 4225 & 4520 & 3494 & 295 & -731 & -18 & -24.65 \\
\hline Mean & 4525 & 4547.5 & 3388.5 & 21 & -136.5 & 7 \\
\hline
\end{tabular}

\section{Rank frequency (matrix ranking)}

Farmers selected shorma as best or good by criteria of quality of disease and pest resistances, better yield, seed color, shuttering resistance and marketability. Also they select shorma variety as best by criteria of Good Seed emergence potential, quality of Disease and pest resistance, seed size, better yield, seed color, shuttering resistance and marketability. Finally they put criteria for kakaba for Good Seed emergence potential, early maturity, and easy for treashablity. According to farmers selection, kakaba were highly susceptible to diseases that they doesn't resist pest and diseases and they are easily affected.

Generally farmers select shorma by $100 \%$ as first, hidase by $93 \%$ as second and kakaba by $14 \%$ as third [4-9] (Table 4). 
Table 4: rank frequency.

\begin{tabular}{|c|c|c|c|c|c|c|c|c|c|c|}
\hline \multirow{3}{*}{ No } & \multirow{3}{*}{ Criteria(N=14) } & \multicolumn{9}{|c|}{ Farmers Rank } \\
\hline & & \multicolumn{3}{|c|}{ Hidase } & \multicolumn{3}{|c|}{ shorma } & \multicolumn{3}{|c|}{ kakaba } \\
\hline & & V.good & Good & Poor & V.good & Good & Poor & V.good & Good & Poor \\
\hline 1 & Good Seed emergence potential & 3 & 88 & 33 & 5 & 88 & 11 & 66 & 66 & 22 \\
\hline 2 & $\begin{array}{l}\text { Quality of Disease and pest } \\
\text { resistance }\end{array}$ & 7 & 7 & - & 7 & 7 & - & - & - & 14 \\
\hline 3 & Early maturity & 1 & 10 & 3 & 4 & 9 & 1 & 9 & 6 & - \\
\hline 4 & Better seed holding per spike & 4 & 10 & - & 5 & 9 & - & 4 & 6 & 4 \\
\hline 5 & Seed size & 4 & 10 & - & 6 & 7 & 1 & 4 & 5 & 5 \\
\hline 6 & Better Yield & 5 & 9 & - & 7 & 7 & - & 2 & 3 & 9 \\
\hline 7 & Seed color & 7 & 6 & 1 & 5 & 9 & - & 2 & 5 & 7 \\
\hline 8 & Easy of treashability & 6 & 6 & 2 & 6 & 6 & 2 & 2 & 8 & 4 \\
\hline 9 & Shuttering resistance & 7 & 7 & - & 6 & 8 & - & 1 & 2 & 11 \\
\hline \multirow[t]{7}{*}{10} & Marketability & 5 & 8 & 1 & 6 & 7 & 1 & 3 & 5 & 6 \\
\hline & Overall & $36.50 \%$ & $56.50 \%$ & $7 \%$ & $41 \%$ & $55 \%$ & $4 \%$ & $23.50 \%$ & $33.50 \%$ & $43 \%$ \\
\hline & Continuity & & & & & & & & & \\
\hline & Yes & 13 & & & 14 & & & 2 & & \\
\hline & No & 1 & & & - & & & 12 & & \\
\hline & Average & 93:07:00 & & & 100:00:00 & & & 0.6431 & & \\
\hline & Rank & 2 nd & & & $1 \mathrm{st}$ & & & $3 \mathrm{rd}$ & & \\
\hline
\end{tabular}

\section{Cost- benefit analysis}

The net benefits that were obtained from shorma was higher than hidase and kakaba. The net benefit of shorma is $33,157.65$ ETB and that of hidase were $32,636.65$ and kakaba 23,428.7

Table 5
ETBs.This indicates that using variety Shorma makes benefit for the farmers $1.57 \%$ and $29.34 \%$ than Hidase and Kakaba respectively and also using variety Hidase increases the income of the for farmers by $28.21 \%$ compared to the using variety Kakaba (Table 5).

\begin{tabular}{|c|c|c|c|c|c|c|}
\hline \multirow[t]{2}{*}{ s.n } & \multirow[t]{2}{*}{ Items } & \multirow[t]{2}{*}{ Quantity } & \multirow[t]{2}{*}{ Unit price/cost } & \multicolumn{3}{|c|}{ Varieties } \\
\hline & & & & Hidase & Shorma & Kakaba \\
\hline 1 & $\begin{array}{l}\text { Average yield (kg/ } \\
\text { hectare) }\end{array}$ & $\mathrm{kg}$ & & 4482 & 4543 & 3404 \\
\hline \multirow[t]{2}{*}{2} & Adjusted yield (-10\%) & & & 4033.8 & 4088.7 & 3064.6 \\
\hline & Total gain & Birr & 9.5 & $38,321.10$ & $38,842.65$ & $29,113.70$ \\
\hline 3 & Seed Cost & $\mathrm{kg}$ & 37 & 925 & 925 & 925 \\
\hline \multirow[t]{3}{*}{4} & Fertilizer costs in kg & NPS & 100 & 1250 & 1250 & 1250 \\
\hline & & Urea & 150 & 1100 & 1100 & 1100 \\
\hline & & Total & 250 & 2350 & 2350 & 2350 \\
\hline 5 & Land preparation cost & ha & 800 & 800 & 800 & 800 \\
\hline \multirow[t]{6}{*}{6} & Labor costs per day & Sowing & 2 day*5person*35birr & 350 & 350 & 350 \\
\hline & & Weeding & 2 day*5person*35birr & 350 & 350 & 350 \\
\hline & & $\begin{array}{l}\text { Fertilizer } \\
\text { application }\end{array}$ & 1day*6person*35birr & 210 & 210 & 210 \\
\hline & & $\begin{array}{l}\text { Harvesting and } \\
\text { transporting }\end{array}$ & 2 day*10person*35birr & 700 & 700 & 700 \\
\hline & Total costs & & & 5685 & 5685 & 5685 \\
\hline & Net Benefit & & & $32,636.10$ & $33,157.65$ & $23,428.70$ \\
\hline
\end{tabular}




\section{Conclusion and Recommendation}

Three varieties of wheat were demonstrated (two newly released and one standard check) with fertilizer rate of $100 \mathrm{~kg}$ per hectare and spacing $20 \mathrm{~cm}$ between rows and drilling. Field day was organized and farmers visit the demonstration plots and select the best varieties according to the listed criteria. The yield performance were 44.82 quintal, 45.43 quintal and 34.04 quintal of Hidase, Shorma and Kakaba respectively and cost benefit analysis were done and 32,636.1 ETB, 33,157.65 ETB, 23,428.7 ETB of Hidase, Shorma and Kakaba respectively.

It is better to disseminate the preferred wheat technologies to a large number of farmers through scaling up of wheat technologies.

To enhance production and productivity, training farmers to apply technologies with its full package including agronomic practices

It is better for future to conduct research on disease resistant and high yielding varieties.

\section{Acknowledgements}

We thank the farmers and development agents DAs in the study without whose active participation this trial would have not been realized; SARI (southern agricultural research institute) and Arbaminch agricultural research center for material and financial support; providing seed and technical backup.

\section{References}

1. MoARD (2005) Meeting the challenge of global climate change and food security.

2. CSA (2012) Federal Democratic Republic of Ethiopia. Agricultural Sample Survey 2011/12 Report on Area and Production of Crops. Central Statically Agency, Addis Ababa, Ethiopia.

3. CSA (2009) Federal Democratic Republic of Ethiopia. Agricultural Sample Survey Report on Area and Production of Crops, Volume I. Central Statically Agency, Addis Ababa, Ethiopia. p. 166.

4. CIMMYT (2014) Wheat improvement - the mandate of CIMMYT's global wheat program. International Maize and Wheat Improvement Center, Mexico.

5. CIMMYT (1988) From Agronomic Data to Farmer Recommendation: An Economics Training Manual. Completely Revised Edition. CIMMYT, Mexico, p. 79.

6. CIMMYT (2000) Enhancing food security in semi arid eastern Indonesia through permanent raised-bed cropping. A review. Mexico, pp. 1035-1045.

7. FAO (2014) Food balance sheets. Faostat. Food and Agriculture Organization, Rome, Italy.

8. Hailu G, Tanner DG, Mengistu H (1991) Wheat Research In Ethiopia: A Historical Perspective.IAR/CIMMYT, Addis Ababa, Ethiopia.

9. Hailu Gebremariam (1991) Wheat Production And Research In Ethiopia. pp. 1-15.

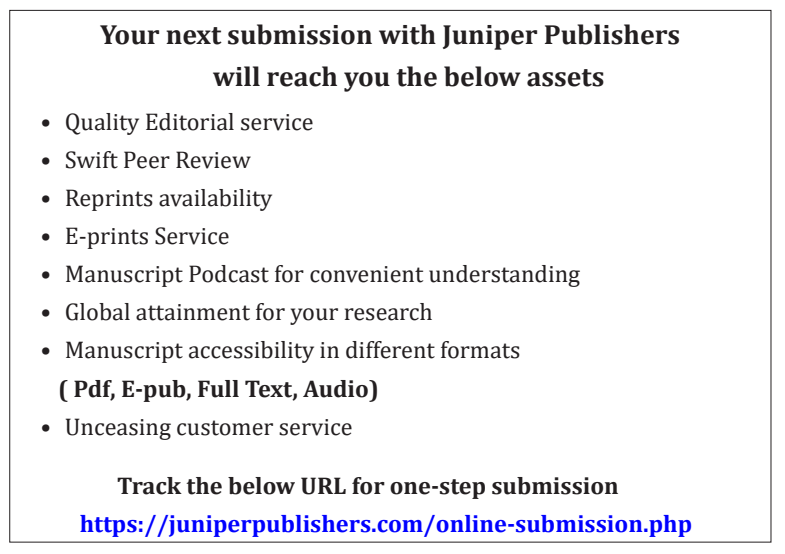

